\title{
Damage Mechanisms in Bithermal and Thermomechanical Fatigue of Haynes 188
}

Sreeramesh Kalluri

Sverdrup Technology, Inc.

Lewis Research Center Group

Brook Park, Ohio

and

Gary R. Halford

Lewis Research Center

Cleveland, Ohio

Prepared for the

Symposium on Thermo-Mechanical Fatigue Behavior of Materials sponsored by the American Society for Testing and Materials

San Diego, California, October 16, 1991

\section{N/Sก}




\title{
DAMAGE MECHANISMS IN BITHERMAL AND THERMOMECHANICAL FATIGUE
}

\section{OF HAYNES 188}

\author{
Sreeramesh Kalluri* \\ Sverdrup Technology, Inc. \\ Lewis Research Center Group \\ Brook Park, Ohio 44142 \\ and \\ Gary R. Halford ${ }^{* *}$ \\ National Aeronautics and Space Administration \\ Lewis Research Center \\ Cleveland, Ohio 44135
}

\section{SUMMARY}

Post failure fractographic and metallographic studies were conducted on Haynes 188 specimens fatigued under bithermal and thermomechanical loading conditions between 316 and $760^{\circ} \mathrm{C}$. Bithermal fatigue specimens examined included those tested under high strain rate in-phase and out-of-phase, tensile creep in-phase, and compressive creep out-of-phase loading conditions. Specimens tested under in-phase and out-of-phase thermomechanical fatigue were also examined. The nature of failure mode (transgranular versus intergranular), the topography of the fracture surface, and the roles of oxidation and metallurgical changes were investigated for each type of bithermal and thermomechanical test.

\section{NOMENCLATURE}

\author{
$t_{f} \quad$ time to failure \\ CCOP compressive creep out-of-phase bithermal fatigue test \\ HRIP high strain rate in-phase bithermal fatigue test \\ HROP high strain rate out-of-phase bithermal fatigue test \\ $\mathrm{N}_{\mathrm{f}}$ number of cycles to failure \\ TCIP tensile creep in-phase bithermal fatigue test \\ TMIP thermomechanical in-phase fatigue test \\ TMOP thermomechanical out-of-phase fatigue test \\ $\sigma_{\text {tens }}$ stress at peak tensile mechanical strain \\ $\sigma_{\text {comp }}$ stress at peak compressive mechanical strain \\ $\Delta \varepsilon_{\text {el }} \quad$ elastic mechanical strain range

\footnotetext{
${ }^{*}$ Research Engineer.

${ }^{* *}$ Senior Research Engineer.
} 


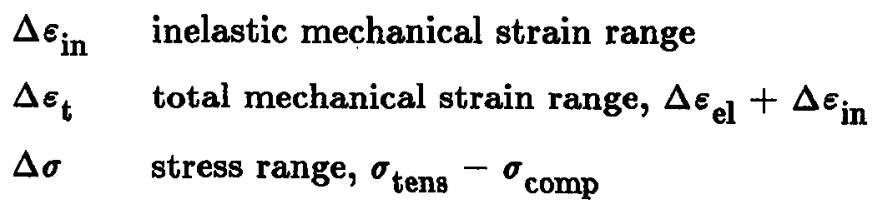

\section{INTRODUCTION}

Thermomechanical fatigue (TMF), where temperature as well as mechanical loading are applied simultaneously to engineering materials, can involve damage mechanisms that differ significantly from those in isothermal fatigue (IF). To understand these mechanisms, it is imperative that extremes in the phasing of thermal and mechanical loading be explored. Investigators commonly perform in-phase (maximum temperature synchronized with the imposed peak tensile strain) and out-of-phase (maximum temperature synchronized with the imposed peak compressive strain) TMF experiments on material specimens (ref. 1). Even though the task of conducting TMF tests has been greatly simplified due to advances in computer-controlled fatigue testing, it is still very time consuming, labor intensive, and consequently expensive, especially at very small mechanical strains. These circumstances have hindered generation and usage of conventional TMF test data as a basis for TMF life prediction modeling.

Bithermal fatigue (BF) testing was originally employed to selectively impose time-dependent inelastic strain (creep) either in tension or in compression during a creep-fatigue cycle (refs. 2 and 3). Halford (ref. 1) summarized bithermal fatigue testing techniques, the simplicity of BF tests over conventional TMF tests, and the prior research by several investigators who had employed BF tests to characterize the fatigue behavior of numerous alloys. A few years ago Halford and his co-workers (ref. 4) proposed BF as a potential link between IF and TMF. The rationale was that the simplified $\mathrm{BF}$ tests which contain two different isothermal segments (tensile and compressive halves of the hysteresis loop) could emulate the damage mechanisms of TMF tests with the same temperature limits.

To verify this philosophy, load-controlled, strain-limited BF tests and strain-controlled TMF tests were conducted on a wrought cobalt-base superalloy, Haynes 188, between the temperatures of 316 and $760{ }^{\circ} \mathrm{C}$. Both in-phase and out-of-phase BF and TMF tests were conducted between these temperature limits. The fatigue life data and the cyclic stress-strain response of Haynes 188 in the BF and TMF tests were previously reported (ref. 5). In the current study, fractography and metallography were conducted on a few selected specimens fatigued to failure in an effort to establish the similarities as well as differences in the fatigue damage mechanisms of BF and TMF for Haynes 188 superalloy. The roles of surface oxidation, grain boundary activity, microstructural changes, and modes of failure in BF and TMF of Haynes 188 are discussed.

\section{MATERIAL DETAILS}

The cobalt-base superalloy, Haynes 188 , is a solid solution strengthened alloy that exhibits high strength, excellent oxidation resistance, and good ductility. Annealed Haynes 188 has a face-centered cubic matrix, a random distribution of $\mathrm{M}_{6} \mathrm{C}$ carbides, and a lanthanum-rich phase that is associated with some of the $\mathrm{M}_{6} \mathrm{C}$ carbides (refs. 6 and 7 ). If Haynes 188 is thermally aged between 704 to $982^{\circ} \mathrm{C}$ then $\mathrm{M}_{23} \mathrm{C}_{6}$ type of carbides are precipitated first at the grain boundaries and later at the twin boundaries as the exposure time is increased (refs. 6 to 8 ). After prolonged exposure times there is a tendency for the formation of Laves phase in 
Haynes 188 (refs. 6 and 7). These metallurgical instabilities increase the hardness and decrease the ductility of Haynes 188 in the post-aged condition compared to the annealed condition. However, ductility of the superalloy can be restored and retained by the material for extended periods (ref. 6) by reannealing at $1178^{\circ} \mathrm{C}$.

Wrought Haynes 188 was purchased in the form of $16 \mathrm{~mm}$-thick rolled plates from a commercial vendor. The as-received material had a hardness of Rockwell " $C$ " 22, which implied a solution-annealed condition (ref. 6). The chemical composition of the superalloy in weight percent was determined to be the following: $<0.0005-\mathrm{S} ;<0.2 \mathrm{ppm}-\mathrm{P} ; 0.06-\mathrm{N}$; 0.1-C; 0.4-Si; $<0.3 \mathrm{ppm}-\mathrm{La} ; 1.6 \mathrm{ppm}-\mathrm{Fe} ; 3.6-\mathrm{Mn} ; 17.8-\mathrm{W} ; 21.0-\mathrm{Ni} ; 22.3-\mathrm{Cr}$ and the balance was cobalt. Microstructure of the as-received material (fig. 1) exhibited grains with a large number of twins and the nominal diameters of the grains varied from 15 to $120 \mu \mathrm{m}$. Typical elastic moduli and tensile properties of Haynes 188 are available in a handbook (ref. 9) and are also listed in references 5 and 10 .

\section{FATIGUE EXPERIMENTS}

\section{Bithermal and Thermomechanical Tests}

Typical BF tests (refs. 1, 4, and 5) consist of two load-controlled, strain-limited, isothermal segments of loading, one each for tensile and compressive halves of the hysteresis loop (fig. 2). Temperature of the specimen is changed between the higher and lower values under zero load in a BF test to facilitate free thermal expansion of the specimen. During an in-phase BF test, the tensile half of the hysteresis loop occurs at the higher isothermal temperature whereas during an out-of-phase BF test it occurs at the lower isothermal temperature. The mechanical and thermal strains are applied to the specimen sequentially in load controlled BF tests as opposed to the conventional strain controlled TMF tests where the mechanical and thermal strains are applied simultaneously to the specimen (fig. 2).

In a $B F$ test at the higher temperature, time-independent inelastic strain (high loading rate) or time-dependent inelastic strain (high loading rate followed by a load-hold) or a combination of the two can be imposed on the specimen (fig. 2). Thus, by properly choosing the temperature limits, loading rates and load levels in a BF test, it is possible to separately induce the timeindependent and -dependent damage mechanisms under nonisothermal conditions (ref. 1). Conventional TMF tests do not permit such a separation of damage mechanisms because of the relatively long cycle times that are required to accommodate the continuous temperature change in a cycle. The BF tests can capture potential thermal free expansion mismatch effect between the oxide layers and substrate (ref. 1). However, there is a possibility of thermal recovery of the material during the temperature changes under zero load in BF tests which is not necessarily present in TMF tests. If simultaneously applied thermal and mechanical strains precipitate some synergistic damage mechanisms in a material then BF would not be able to capture such damage mechanisms (ref. 11). In summary, BF tests can capture some of the damage mechanisms that prevail in conventional TMF tests. For additional details on bithermal and thermomechanical fatigue tests the reader is referred to references 1,4 , and 5 . 


\section{Specimens and Test Equipment}

Hourglass fatigue specimens (ref. 10) with a minimum test section diameter of $6.4 \mathrm{~mm}$ were machined with the longitudinal axis of the specimen parallel to the final rolling direction of the Haynes 188 plates. Test specimens were heated to the required test temperature in air by a direct resistance method and the control of temperature was accomplished by chromel-alumel thermocouples spot-welded to the specimen at a calibrated location $5 \mathrm{~mm}$ away from the minimum cross section of the hourglass specimen. This was done to prevent premature cracking from thermocouple spot-welds near the minimum cross section of the fatigue specimen. All the tests were conducted on a uniaxial servohydraulic fatigue rig. Test control was performed with a commercially available minicomputer interfaced to the hydraulic and temperature servocontrollers. A diametral extensometer described in detail by Hirschberg (ref. 12) was used to measure displacements at the minimum cross-section of the specimen. Additional details on specimen geometry, temperature measurement techniques, and test equipment are available in reference 10.

\section{Fatigue Data}

Bithermal and thermomechanical fatigue tests were conducted between 316 and $760^{\circ} \mathrm{C}$ on Haynes 188 hourglass fatigue specimens (ref. 5). Bithermal in-phase (HRIP and TCIP) and outof-phase (HROP and CCOP) fatigue tests were conducted by first cycling the specimen for a few cycles between the higher and lower temperatures (under load control at zero load) to obtain stabilized thermal strains and then superimposing the required mechanical strains to obtain the total strain limits for the test. For each bithermal cycle, the temperature variation time was $180 \mathrm{~s}$, with $75 \mathrm{~s}$ for heating (direct resistance) and $105 \mathrm{~s}$ for cooling (conduction and natural convection). The total time per cycle in a BF test depended upon the specific loading condition. Both in-phase (TMIP) and out-of-phase (TMOP) TMF tests were conducted under straincontrol with a cycle time of $180 \mathrm{~s}$. Failure in BF and TMF tests was defined as a 50 percent drop in the tensile peak load from the stabilized value. Additional details on the procedures adopted for performing the BF and TMF tests are documented in references 5 and 10. For BF and TMF tests, the measured diametral displacements were converted to longitudinal strains by using the procedure described in reference 5.

All the bithermal and thermomechanical fatigue data generated on Haynes 188 between the temperatures of 316 and $760^{\circ} \mathrm{C}$, the corresponding fatigue life relationships, and the cyclic stress-strain relationships were reported earlier (ref. 5). In this study, one failed fatigue specimen from each of the four types of BF tests (HRIP, HROP, TCIP, and CCOP) and the two types of TMF tests (TMIP and TMOP) was selected to conduct fractographic and metallographic investigations. The test type, test parameters, and fatigue life corresponding to each of the selected specimens are listed in table I. Cycle times of the TCIP and CCOP tests were longer than the cycle times of the HRIP, HROP, TMIP, and TMOP tests. In table I, the reported strain ranges are longitudinal mechanical strain ranges. Samples selected for observation had a total strain range, $\Delta \varepsilon_{t}$ of approximately 1 percent.

\section{FRACTOGRAPHY}

From each selected fatigue specimen, one half was used for fractography and the other for metallographic investigation of a longitudinal section. The fractographic samples were sputter 
coated with palladium to improve the fracture surface images in a scanning electron microscope. Fatigue cracks initiated at the surface in all BF and TMF test specimens.

In the bithermal HRIP and HROP tests (table I), as in the case of an isothermal high rate strain cycling fatigue test, transgranular cracking and fatigue striations were observed (fig. 3). A larger number of striations was visible in the HROP test than in the HRIP test. This is possibly due to the higher cyclic life of the HROP test (table I). In both cases the observed striations exhibited nonuniform spacing and direction which indicated an irregular crack front movement compared to classic fatigue striations. These striations are referred to as "distorted" striations. The "distorted" striations indicate the presence of secondary grain boundary activity possibly caused by crystallographic slip in these types of bithermal tests.

In the bithermal TCIP test, fracture surface topography indicated intergranular cracking and no striations were observed (fig. 4). Multiple regions of intergranular cracking were observed and the area between these regions failed in a ductile, tearing mode. On the contrary, the fracture surface of the bithermal CCOP test exhibited a transgranular mode of failure and heavily "distorted" striations (fig. 5), possibly due to grain boundary sliding in compressive creep and the subsequent tensile plasticity. Similar fractographic features were observed for an austenitic stainless steel under isothermal, tensile creep reversed by compressive plasticity, and compressive creep reversed by tensile plasticity, cyclic loading conditions (refs. 13 and 14).

Fracture surface topography for the thermomechanical TMIP test was distinctly intergranular with no striations (fig. 6). These fracture surface features are similar to those observed in the bithermal TCIP test (fig. 4). In the case of the TMOP test the fracture surface was transgranular with mildly "distorted" striations (fig. 7). However, occasional regions of intergranular fracture were also observed. The mildly "distorted" striations indicate a lower level of grain boundary activity in the TMOP test as compared to the CCOP test.

In general, fracture surfaces of in-phase tests exhibited more oxidation then their counterpart out-of-phase tests for both bithermal and thermomechanical fatigue tests.

\section{METALLOGRAPHY}

\section{Oxidation}

Specimens were longitudinally sectioned and mounted in bakelite to preserve the oxide laden edges during sample preparation. The polished specimens were then photographed before etching (to preserve the oxide layer) with an optical microscope to document the oxidation patterns in each bithermal and thermomechanical test. For the metallographic photographs presented in this paper (figs. 8 to 15), vertical direction of the page corresponds to the mechanical loading direction of the hourglass fatigue specimen. No discernible oxide formed in the bithermal HRIP test on the external surface of the specimen. In the case of the bithermal HROP test very small amounts of oxide were noticed near the opened fracture surface. In the bithermal TCIP test oxide formed along the grain boundaries and secondary cracks (fig. 8(a); grey colored regions are oxides). Extensive formation of oxide was observed on the fracture and external surfaces of the bithermal CCOP test specimen (fig. 8(b)). In this test the specimen was subjected to the lowest creep stress at high temperature for the longest amount of time among the four bithermal tests. In the TMIP test, small amounts of oxide were observed in the intergranular cracks (fig. 9(a)). The oxidation pattern in the TMIP test is similar to that in the TCIP test (fig. 8(a)). 
Moderate amounts of oxide were formed on the side of the specimen and along the main crack that caused failure in the TMOP test (fig. 9(b)). The thickness of oxide scale formed in the TMOP test was less than that formed in the CCOP test (fig. 8(b)), which had a longer time to failure.

\section{Microstructure}

After examining all metallographic samples for oxidation, they were electrolytically etched in 5 percent hydrochloric acid solution with $4 \mathrm{~V}-0.5 \mathrm{~A}$ current for 1 to $5 \mathrm{~s}$. The microstructures of all specimens tested under bithermal and thermomechanical tests displayed precipitation of carbides, most likely $\mathrm{M}_{23} \mathrm{C}_{6}$, predominantly along the grain boundaries and sometimes along the twin boundaries as reported in references 6 to 8 . The testing time involved in these fatigue experiments was less than $200 \mathrm{hr}$ which precluded the formation of Laves phase (refs. 6 and 7 ).

A secondary crack that was close to the fracture surface in the bithermal HRIP test is shown in figure 10. Evidence of grain boundary carbide precipitation is also seen in the HRIP test. In the bithermal HROP test (fig. 11), the following were observed: Small amounts of $\mathrm{M}_{23} \mathrm{C}_{6}$ carbides within the grains (in addition to the precipitation along the grain and twin boundaries) and crystallographic slip that produced distortion of the twin boundaries. The microstructures of bithermal HRIP and HROP tests, while exhibiting subtle differences, were basically similar. In the TCIP test, precipitation and accumulation of $\mathrm{M}_{23} \mathrm{C}_{6}$ carbides along the grain boundaries and cracking of transversely oriented grain boundaries were noticed (fig. 12). In the CCOP test, transgranular fracture, distortion of grains and twins due to plastic deformation (probably due to tensile overload at the end of the test), occurred in addition to the intergranular precipitation of carbides (fig. 13).

Microstructure of the in-phase TMF test (fig. 14) indicated small amounts of intergranular $\mathrm{M}_{23} \mathrm{C}_{6}$ carbide precipitation and an accumulation of these carbides in some locations. Intergranular fracture along the main crack that caused failure and at other locations is distinctly visible in figure 14. Intergranular carbide precipitation and cracking within the longitudinal grain boundaries near the fracture surface were observed in a TMOP test (fig. 15). However, the main crack that caused failure in the TMOP test was transgranular. Table II summarizes the fractographic and metallographic observations.

\section{DISCUSSION}

The bithermal HRIP and HROP tests, due to their high rate of loading, excluded timedependent creep deformation. The fracture surfaces exhibited transgranular cracking and slightly "distorted" striations (fig. 3). Among the bithermal tests that contained creep the TCIP test exhibited intergranular cracking and no striations (fig. 4) whereas the CCOP test exhibited transgranular fracture and highly "distorted" striations (fig. 5). These results indicate that formation of striations occurred both at 316 and $760{ }^{\circ} \mathrm{C}$ in $\mathrm{BF}$ tests whenever tensile timeindependent plastic deformation was applied. The highly "distorted" striations in the bithermal out-of-phase CCOP test indicate a higher level of interaction between the striations and the grain boundaries they intersect than encountered in the bithermal out-of-phase HROP test. Since the CCOP test involved compressive creep instead of compressive plasticity at $760{ }^{\circ} \mathrm{C}$, it is inferred that this creep deformation contributed to the interaction between the grain 
boundaries and striation formation. Potential mechanisms for such an interaction might be grain boundary sliding, intergranular carbide precipitation, or a combination of both.

It is indicated earlier in the paper that most of the fracture surface features of the TCIP and TMIP tests (figs. 4 and 6) as well as the CCOP and TMOP tests (figs. 5 and 7) were similar. Such a resemblance for Haynes 188 indicates the absence of synergistic damage mechanisms in TMF due to simultaneous application of temperature and mechanical loads within the temperature range of 316 to $760{ }^{\circ} \mathrm{C}$. The resemblance between the fracture surfaces of BF and TMF tests is not unexpected because the TMF tests, both in-phase and out-of-phase, embody the same deformation modes as those in the BF tests. For instance in the TMIP test, creep and plasticity are applied in tension with plasticity in compression, which is similar to the combination of deformations in TCIP and HRIP tests. Likewise in a TMOP test, creep and plasticity are applied in compression with plasticity in tension, which is similar to the deformation in a combination of CCOP and HROP tests.

In both the BF and TMF tests (except in the CCOP test) the thicknesses of the oxide layers are small (figs. 8 and 9). This is a testimony to the oxidation resistance of Haynes 188.

However, at temperatures greater than $760^{\circ} \mathrm{C}$ oxidation may play an important role in limiting the fatigue life of Haynes 188. Oxides formed mainly along the grain boundaries in the bithermal TCIP and thermomechanical TMIP tests (figs. 8 and 9). No oxidation of grain boundaries was noticed in the CCOP and TMOP tests. Instead, in these tests oxides formed on the outer specimen surfaces and along the main transgranular cracks that caused fatigue failure. These observations indicate that the formation of oxide along the grain boundaries is prevalent in the presence of tensile creep which is common for both the TCIP and TMIP tests.

In the BF as well as TMF tests, the microstructure of the failed samples revealed precipitation of $\mathrm{M}_{23} \mathrm{C}_{6}$ carbides mainly along the grain boundaries. Precipitation and accumulation of carbides along the grain boundaries and cracking of the transversely oriented grain boundaries were noticed in the TCIP and TMIP tests (figs. 12 and 14). Grain boundary carbide precipitation and accumulation were also observed in both CCOP and TMOP tests. However, cracking within the longitudinally oriented grain boundaries was observed in some areas only in the TMOP test (figs. 15). The significance of this observation is unknown. It is believed that the accumulation of carbide precipitates in the grain boundaries caused embrittlement and made them susceptible to fracture at prolonged exposure times. Thus, several similarities exist in the modes of cracking, formation of oxide layers, and metallurgical microstructures among the inphase and out-of-phase BF and TMF fatigue tests of Haynes 188. These similarities provide phenomenological bases for the utilization of bithermal fatigue data in thermomechanical fatigue life prediction. Indeed, Halford et al. (ref. 15) successfully predicted the in-phase and out-ofphase TMF fatigue lives of Haynes 188 to within a factor 2 by using the BF data reported in reference 5 . However, it must be pointed out that the similarities between the damage mechanisms of BF and TMF tests may not exist for other materials and temperature regimes. Thus, it is the responsibility of fatigue life estimator to ascertain that there are indeed similar damage mechanisms occurring in BF and TMF tests before attempting to use the BF data as the basis for TMF life prediction.

\section{CONCLUSIONS}

Fractographic and metallographic investigations were conducted on six specimens of Haynes 188 that were fatigued to failure under in-phase and out-of-phase bithermal and 
thermomechanical loading conditions between 316 and $760^{\circ} \mathrm{C}$. These investigations identified the prevailing damaging mechanisms in both bithermal and thermomechanical fatigue tests.

Bithermal fatigue specimens tested under high strain rates (in-phase as well as out-of-phase) exhibited mildly "distorted" striations, transgranular cracking, and small amounts of surface oxidation. Fatigue specimens of in-phase bithermal and thermomechanical tests involving tensile creep cracked in intergranular fashion with oxidation primarily along the grain boundaries. In out-of-phase bithermal and thermomechanical fatigue test specimens subjected to compressive creep, transgranular cracking and surface oxidation were observed. In all the specimens examined precipitation of carbides were noticed primarily along the grain boundaries and occasionally along the twin boundaries and within the grains. Among the tests that imposed creep loading on the specimens, cracking of transverse grain boundaries was observed in in-phase bithermal and thermomechanical fatigue tests whereas longitudinal grain boundary cracking was observed in only the out-of-phase thermomechanical fatigue test.

Based on the similarities that exist among the damage mechanisms of bithermal and thermomechanical fatigue tests it was concluded that for Haynes 188 between 316 and $760^{\circ} \mathrm{C}$, bithermal fatigue tests could be used as the basis for thermomechanical fatigue life prediction. However, this conclusion needs to be generalized for other materials, temperature regimes, and environmental conditions.

\section{ACKNOWLEDGMENT}

Mr. Ralph Corner and Mr. Todd Leonhardt meticulously prepared and photographed the samples for the fractographic and metallographic studies.

\section{REFERENCES}

1. Halford, G.R.: Low-Cycle Thermal Fatigue. Thermal Stresses II, R.B. Hetnarski, ed., Elsevier Science Publishers, 1987, pp. 330-428.

2. Manson, S.S.; Halford, G.R.; and Hirschberg, M.H.: Creep-Fatigue Analysis by Strain-Range Partitioning. Symposium on Design for Elevated Temperature Environment, S.Y. Zamrik, ed., American Society for Mechanical Engineers, 1971, pp. 12-28.

3. Halford, G.R.; Hirschberg, M.H.; and Manson, S.S.: Temperature Effects on the Strainrange Partitioning Approach for Creep Fatigue Analysis. Fatigue at Elevated Temperatures, ASTM STP 520, A.E. Carden, A.J. McEvily, and C.M. Wells, eds., American Society for Testing and Materials, 1973, pp. 658-667.

4. Halford, G.R.; et al.: Bithermal Fatigue: A Link Between Isothermal and Thermomechanical Fatigue. Low Cycle Fatigue, ASTM STP 942, H.D. Soloman, et al., eds., American Society for Testing and Materials, 1988, pp. 625-637.

5. Halford, G.R.; et al.: Thermomechanical and Bithermal Fatigue Behavior of Cast B1900+Hf and Wrought Haynes 188. Advances in Fatigue Lifetime Predictive Techniques, ASTM STP 1122, M.R. Mitchell and R.W. Landgraf, eds., American Society for Testing and Materials, 1992, pp. 120-142. 
6. Herchenroeder, R.B.: Haynes Alloy No. 188 Aging Characteristics. Proceedings of the International Symposium on Structural Stability in Superalloys, Vol. 2, ASTM/ASME/ AMS/AIME, Seven Springs, PA, 1968, pp. 460-500.

7. Herchenroeder, R.B.; and Ebihara. W.T.: In-Process Metallurgy of Wrought Cobalt-Base Alloys. Met. Eng. Q., Vol. 9, May 1969, pp. 30-41.

8. Matthews, S.J.: Thermal Stability of Solid Solution Strengthened High Performance Alloys. Superalloys: Metallurgy and Manufacture, Proceedings of the Third International Symposium, B.H. Kear, et al., ed., Claitor's Publishing Division, Baton Rouge, Louisiana, 1976, pp. 215-226.

9. Nickel Base Alloys. International Nickel Company, Inc., New York, 1977.

10. Halford, G.R.; Saltsman, J.F.; and Kalluri, S.: High Temperature Fatigue Behavior of Haynes 188. Advanced Earth-to-Orbit Propulsion Technology Conference, NASA CP-3012, Vol. I, R.J. Richmond and S.T. Wu, eds., 1988, pp. 497-509.

11. Verrilli, M.J.: Bithermal Fatigue of a Nickel-Base Superalloy Single Crystal. NASA TM-100885, 1988, pp. 1-13.

12. Hirschberg, M.H.: A Low Cycle Fatigue Testing Facility. Manual on Low Cycle Fatigue Testing, ASTM STP 465, American Society for Testing and Materials, 1969, pp. 67-86.

13. Kalluri, S.; Manson, S.S.; and Halford, G.R.: Exposure Time Considerations in High Temperature Low Cycle Fatigue. Mechanical Behavior of Materials - V, Proceedings of the Fifth International Conference, Beijing, People's Republic of China, M.G. Yan, S.H. Zhang, and Z.M. Zheng, eds., Pergamon Press, 1988, Vol. 2, pp. 1029-1036.

14. Kalluri, S.; Manson, S.S.; and Halford, G.R.: Environmental Degradation of 316 Stainless Steel in High Temperature Low Cycle Fatigue. Environmental Degradation of Engineering Materials III, M.R. Louthan, Jr., R.P. McNitt, and R.D. Sisson, eds., The Pennsylvania State University, University Park, PA, 1987, pp. 503-519.

15. Halford, G.R., et al.: Application of a New Thermal Fatigue Life Prediction Model to Two High-Temperature Aerospace Alloys B1900 + Hf and Haynes 188. Advances in Fatigue Lifetime Predictive Techniques, ASTM STP 1122, M.R. Mitchell and R.W. Landgraf, eds., American Society for Testing and Materials, 1992, pp. 107-119. 
TABLE I.-BITHERMAL AND THERMOMECHANICAL FATIGUE DATA OF HAYNES $188^{\mathrm{a}}$

\begin{tabular}{|c|c|c|c|c|c|c|c|c|c|}
\hline $\begin{array}{l}\text { Test } \\
\text { type }\end{array}$ & $\begin{array}{c}\text { Temperature }^{\mathrm{b}} \text {, } \\
{ }^{\circ} \mathrm{C}\end{array}$ & $\begin{array}{c}\Delta \varepsilon_{\mathrm{el}}, \\
\text { percent }\end{array}$ & $\begin{array}{c}\Delta \varepsilon_{\text {in }} \\
\text { percent }\end{array}$ & $\begin{array}{c}\Delta \varepsilon_{\mathrm{t}} \\
\text { percent }\end{array}$ & $\begin{array}{r}\sigma_{\text {tens }} \\
\mathrm{MPa} \\
\end{array}$ & $\begin{array}{c}\sigma_{\text {comp' }} \\
\mathrm{MPa}\end{array}$ & $\begin{array}{c}\Delta \sigma \\
\mathrm{MPa}\end{array}$ & $\mathbf{N}_{\mathrm{f}}$ & $\begin{array}{l}\mathrm{t}_{\mathrm{f}}^{\mathrm{c}} \\
\mathrm{hr}\end{array}$ \\
\hline HRIP & $760<->316$ & 0.60 & 0.35 & 0.95 & 541 & -598 & 1139 & 1421 & 78.9 \\
\hline HROP & $316<->760$ & .63 & .34 & .97 & 620 & -570 & 1190 & 2799 & 163.2 \\
\hline TCIP & $760<->316$ & .50 & .21 & .71 & 379 & -583 & 962 & 1940 & 137.8 \\
\hline $\mathrm{CCOP}$ & $316<->760$ & .50 & .56 & 1.06 & 664 & -299 & 963 & 647 & 133.9 \\
\hline TMIP & $760<->316$ & .70 & .46 & 1.16 & 543 & -794 & 1337 & 829 & 41.1 \\
\hline TMOP & $316<->760$ & .56 & .27 & .83 & 661 & -415 & 1076 & 720 & 36.0 \\
\hline
\end{tabular}

${ }^{a}$ Data from reference 5 .

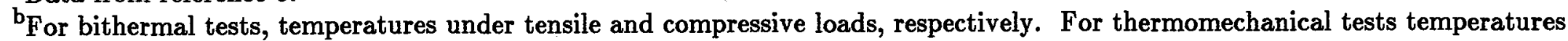
at peak tensile and compressive strains, respectively.

${ }^{c}$ For bithermal tests, $t_{f}$ values include the temperature cycling time of 3 mins/cycle. 
TABLE II.-SUMMARY OF DAMAGE MECHANISMS IN BITHERMAL AND THERMOMECHANICAL

FATIGUE OF HAYNES 188

\begin{tabular}{|c|c|c|c|c|c|}
\hline $\begin{array}{l}\text { Test } \\
\text { type }\end{array}$ & $\begin{array}{c}\text { Grain boundary } \\
\text { carbide } \\
\text { precipitation }\end{array}$ & $\begin{array}{l}\text { Intergranular } \\
\text { cracking }\end{array}$ & $\begin{array}{l}\text { Transgranular } \\
\text { cracking }\end{array}$ & $\begin{array}{l}\text { Striation } \\
\text { formation }\end{array}$ & $\begin{array}{l}\text { Location and } \\
\text { extent of } \\
\text { oxidation } \\
\end{array}$ \\
\hline HRIP & $\checkmark$ & & $\checkmark$ & $\checkmark$ & $\begin{array}{l}\text { Small amounts on } \\
\text { fracture surface }\end{array}$ \\
\hline HROP & $\checkmark$ & & $\checkmark$ & $\checkmark$ & $\begin{array}{l}\text { Very small amounts near } \\
\text { the opened fracture sur- } \\
\text { face }\end{array}$ \\
\hline TCIP & 8 & 1 & & & $\begin{array}{l}\text { Medium amounts on the } \\
\text { fracture surface and } \\
\text { within the secondary } \\
\text { cracks along the grain } \\
\text { boundaries }\end{array}$ \\
\hline TMIP & 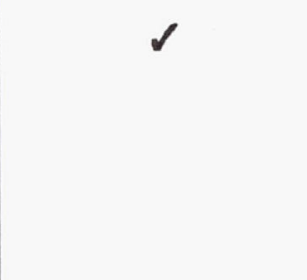 & $\checkmark$ & & & $\begin{array}{l}\text { Medium amounts on the } \\
\text { fracture surface and } \\
\text { within the secondary } \\
\text { cracks along the grain } \\
\text { boundaries }\end{array}$ \\
\hline CCOP & $\checkmark$ & & $s$ & $\checkmark$ & $\begin{array}{l}\text { Large amounts on the } \\
\text { fracture and external } \\
\text { surfaces }\end{array}$ \\
\hline TMOP & $\checkmark$ & & $\checkmark$ & $\checkmark$ & $\begin{array}{l}\text { Medium amount on the } \\
\text { fracture surface and } \\
\text { large amount on the } \\
\text { external surface }\end{array}$ \\
\hline
\end{tabular}




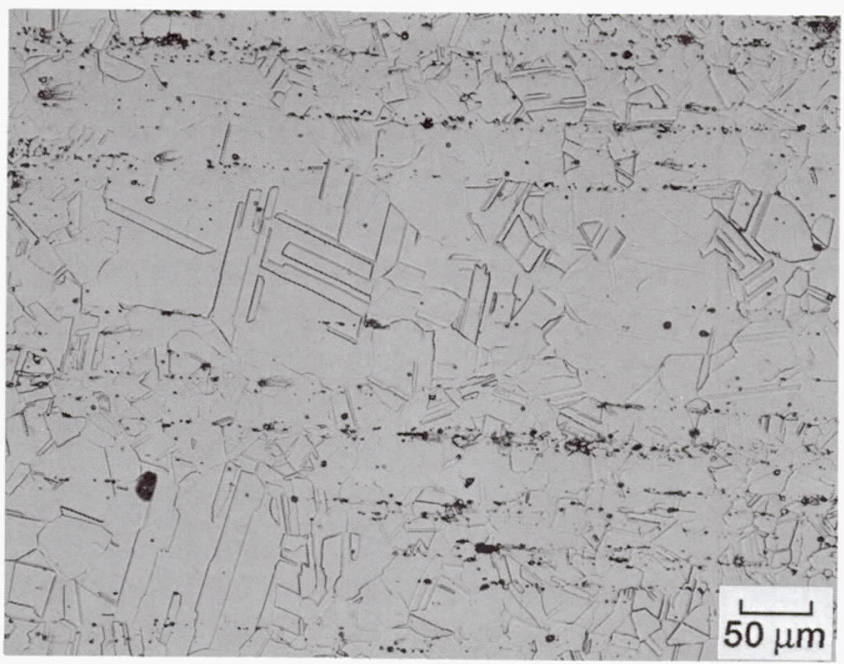

Figure 1.-Microstructure of as-received Haynes 188.

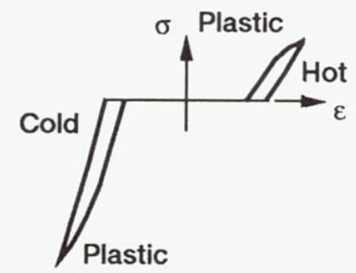

(a)

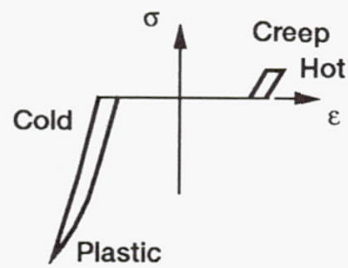

(c)

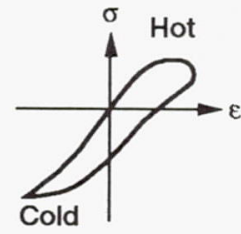

(e)

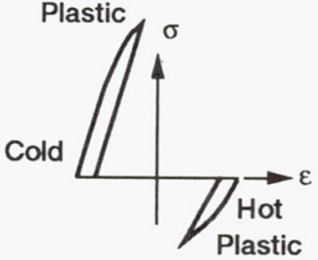

(b)

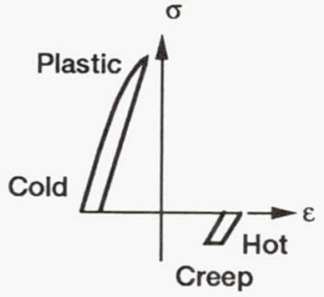

(d)

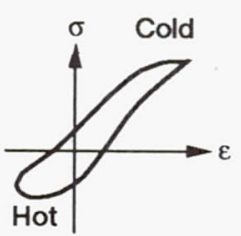

(f)

(a) Bithermal high rate in-phase test (HRIP).

(b) Bithermal high rate out-of-phase test (HROP).

(c) Bithermal tensile creep in-phase test (TCIP).

(d) Bithermal compressive creep out-of-phase test (CCOP).

(e) Thermomechanical in-phase test (TMIP).

(f) Thermomechanical out-of-phase test (TMOP).

Figure 2.-Schematic hysteresis loops of bithermal and thermomechanical fatigue tests. 


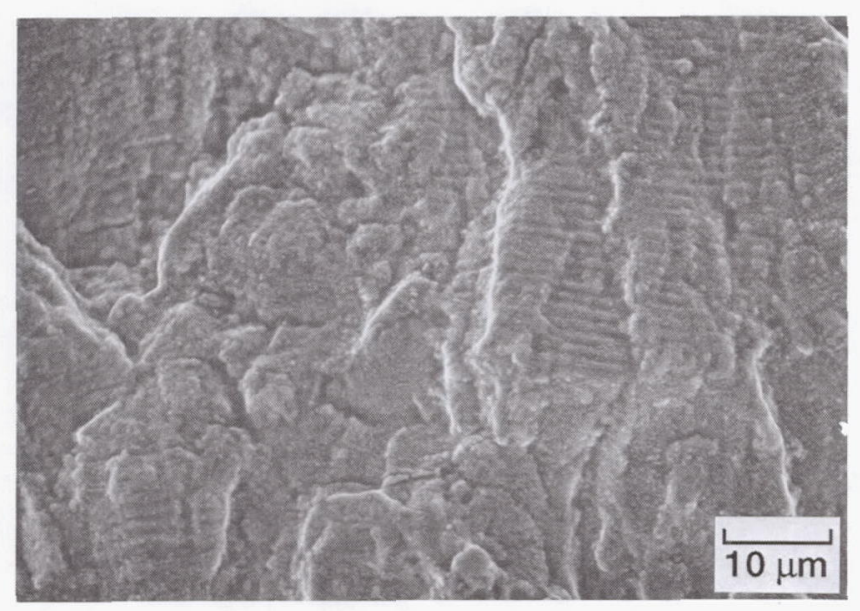

(a) HRIP test.

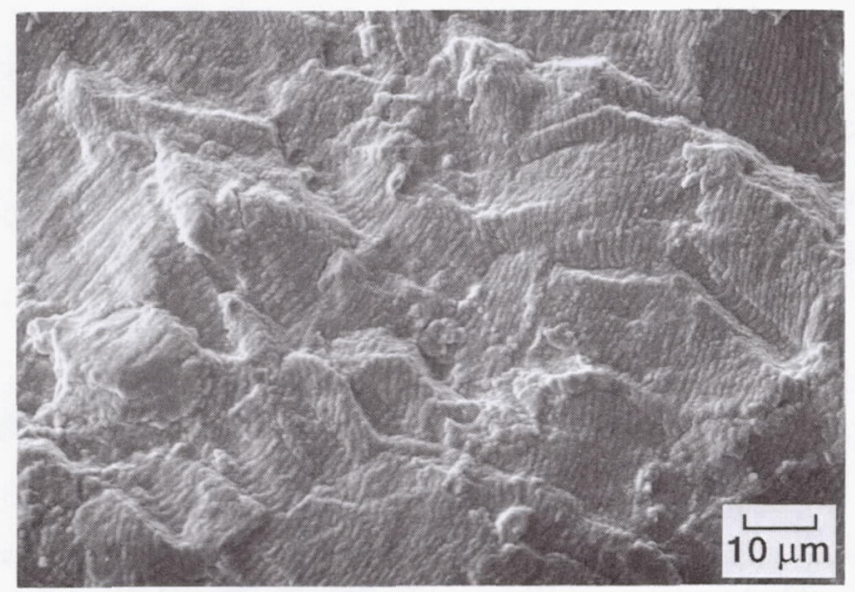

(b) HROP test.

Figure 3.-Transgranular fracture and striations in bithermal fatigue tests.

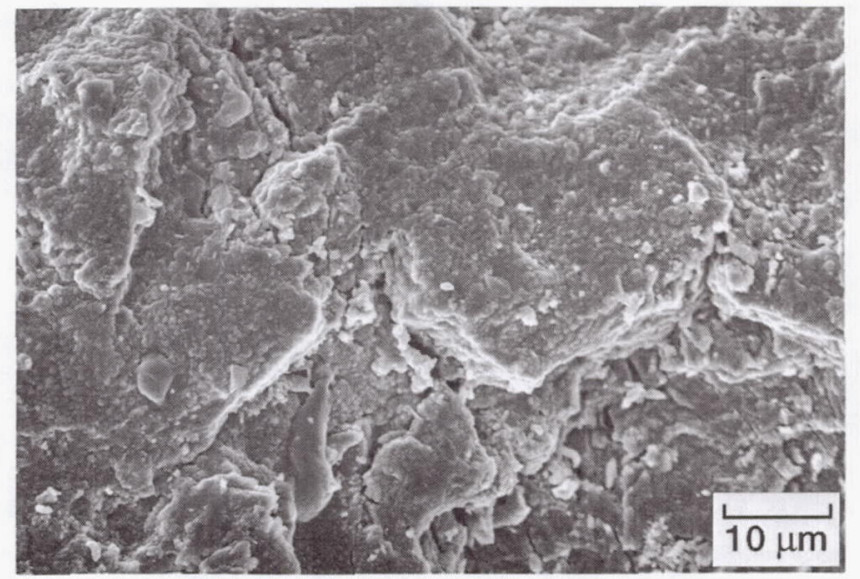

Figure 4.--Intergranular cracking in bithermal TCIP test. 


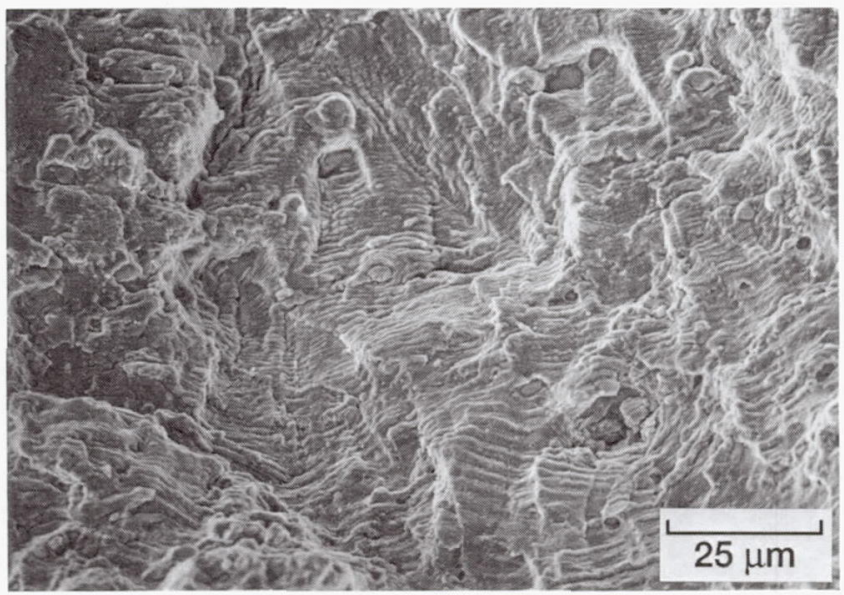

Figure 5.-Transgranular cracking and heavily distorted striations in bithermal CCOP test.

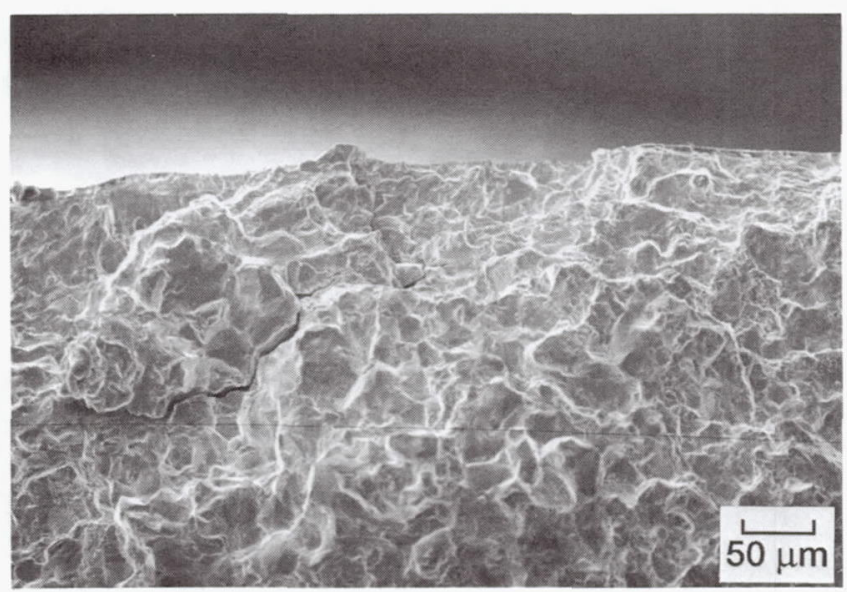

Figure 6.-Intergranular fracture in TMIP test.

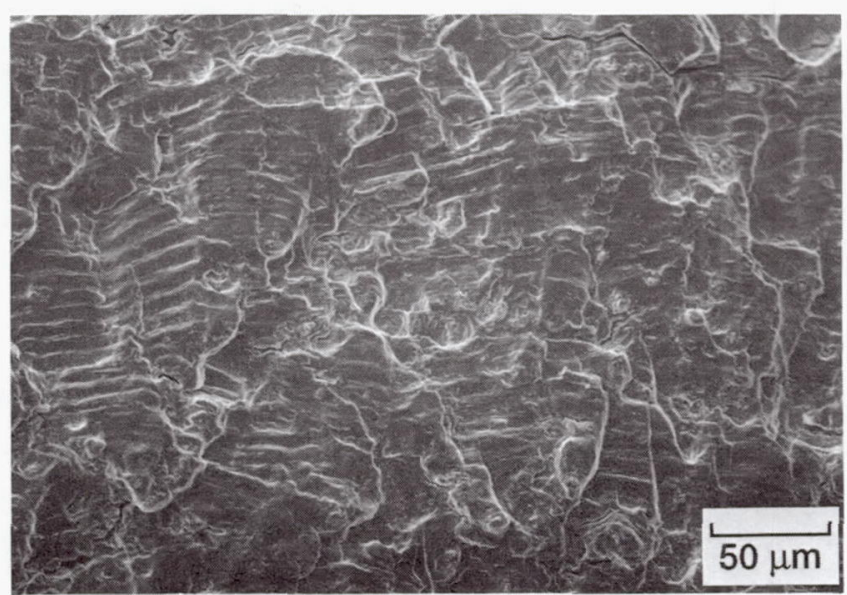

Figure 7.-Transgranular fracture and mildly distorted striations in TMOP test. 


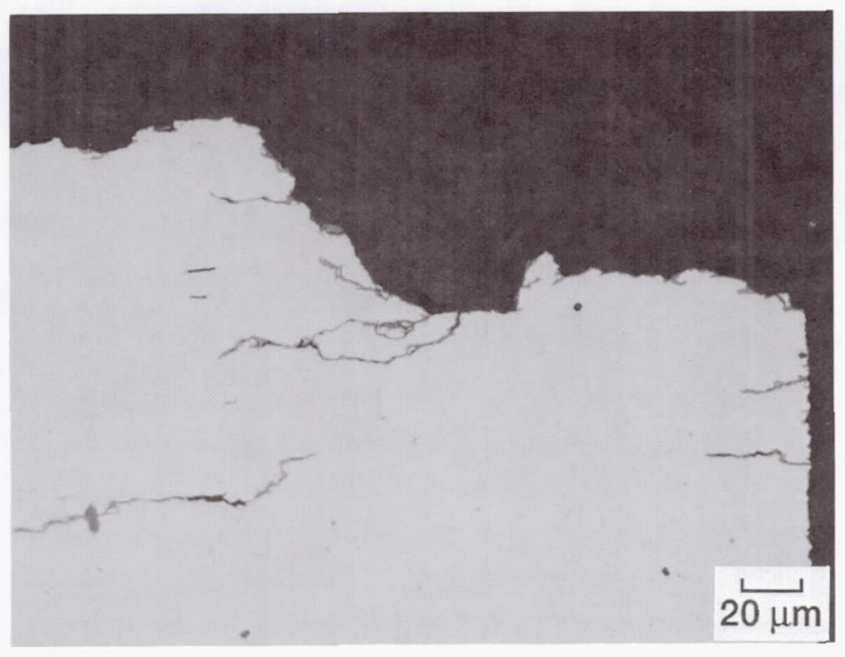

(a) TCIP test.

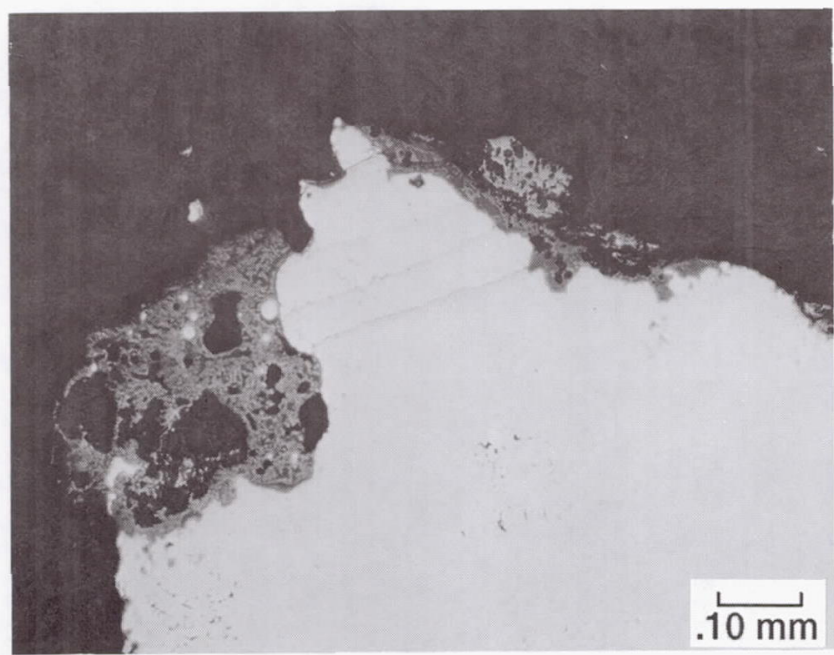

(b) CCOP test.

Figure 8.-Oxide formation in bithermal tests.

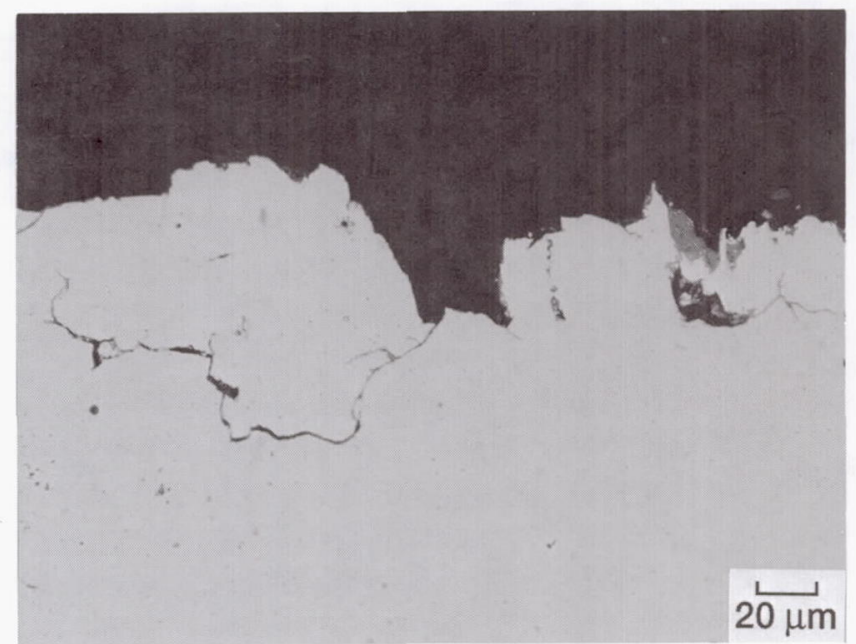

(a) TMIP test.

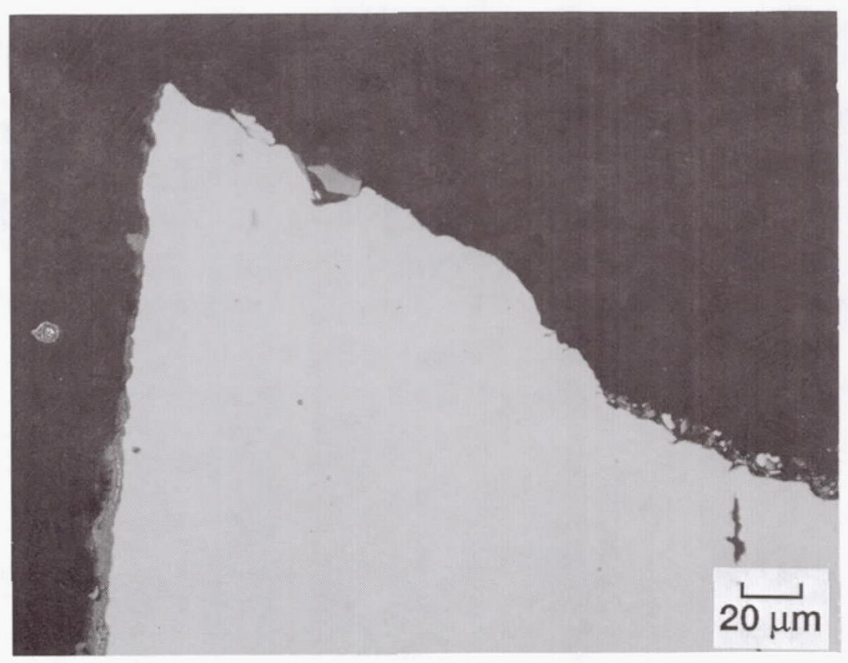

(b) TMOP test.

Figure 9.-Oxide formation in thermomechanical tests. 


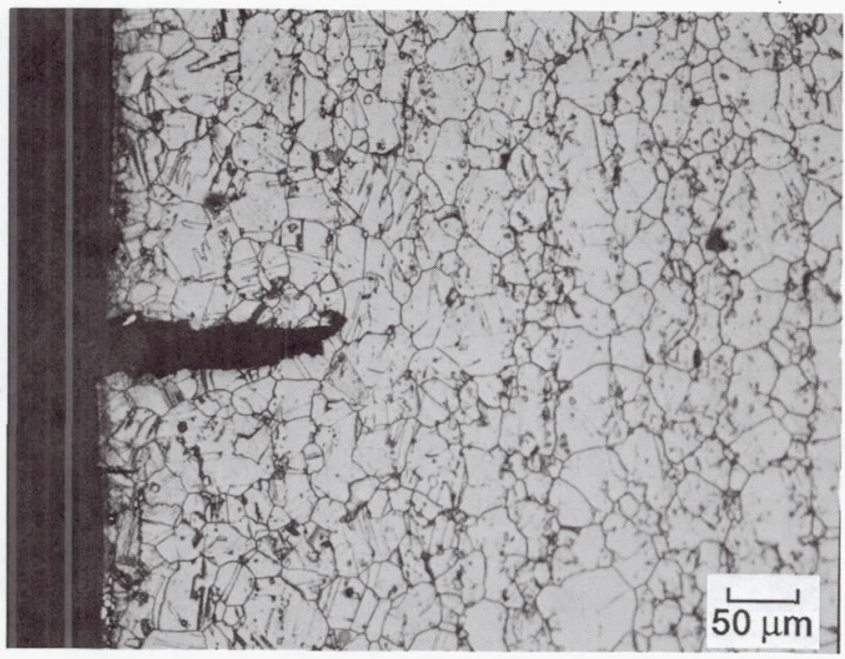

Figure 10.-Secondary crack in the bithermal HRIP test.

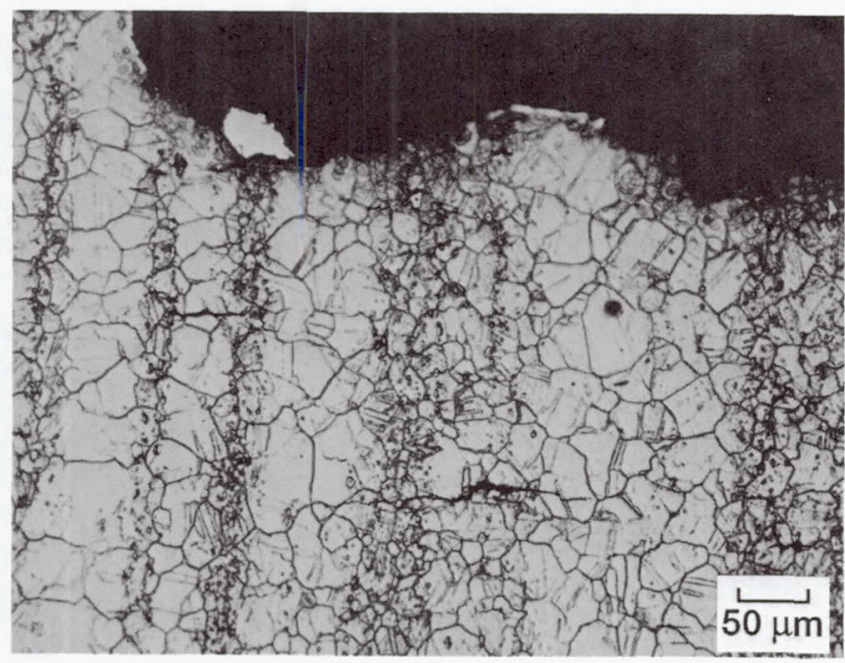

Figure 12.-Grain boundary carbide precipitation and cracking of transverse grain boundaries in the bithermal TCIP test.

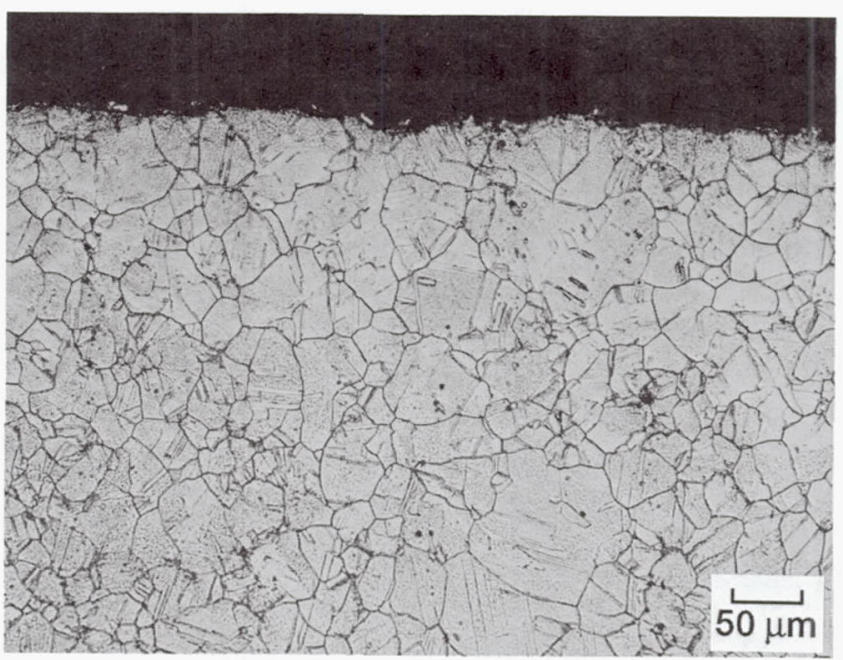

Figure 11.-Intragranular precipitation of carbides, distortion of twins, and slip plane activity in the bithermal HROP test.

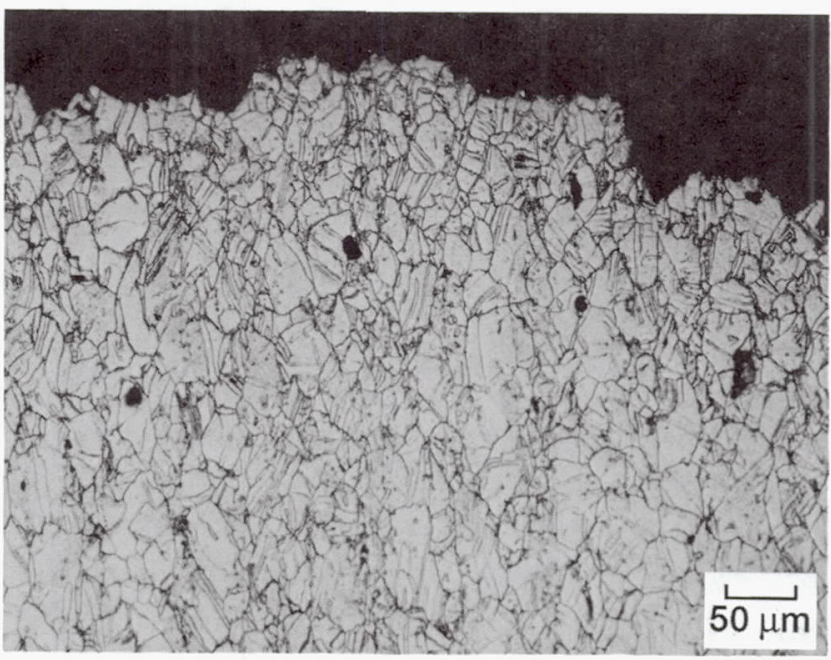

Figure 13.-Transgranular cracking, distortion of twins, and precipitation of carbides in the bithermal CCOP test. 


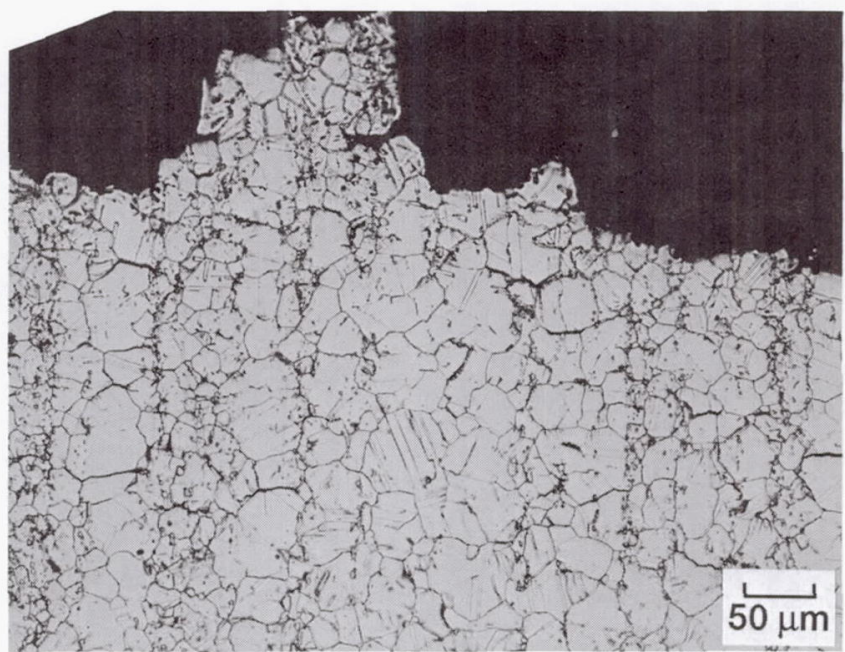

Figure 14.- Intergranular carbide precipitation and fracture in TMIP test.

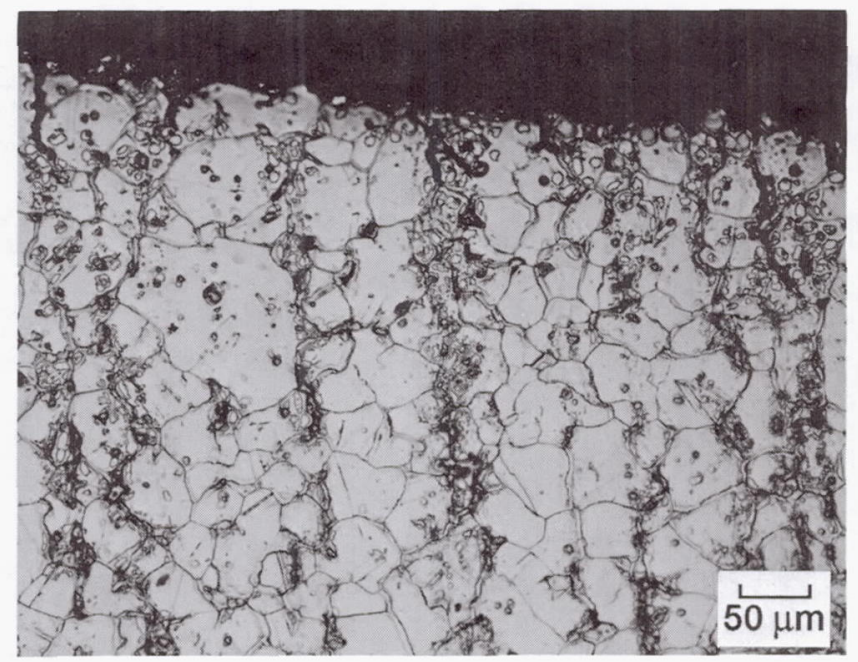

Figure 15.- Intergranular carbide precipitation and transgranular fracture in TMOP test. 


Public reporting burden for this collection of information is estimated to average 1 hour per response, including the time for reviewing instructions, searching existing data sources, gathering and maintaining the data needed, and completing and reviewing the collection of information. Send comments regarding this burden estimate or any other aspect of this collection of information, including suggestions for reducing this burden, to Washington Headquarters Services, Directorate for information Operations and Reports, 1215 Jefferson Davis Highway, Suite 1204, Arlington, VA 22202-4302, and to the Office of Management and Budget, Paperwork Reduction Project (0704-0188), Washington, DC 20503.

\begin{tabular}{|l|l|l|}
\hline 1. AGENCY USE ONLY (Leave blank) & 2. REPORT DATE & 3. REPORT TYPE AND DATES COVERED
\end{tabular}

\begin{tabular}{|l|l|l}
\hline & 1992 & Technical Memorandum \\
\hline
\end{tabular}

4. TITLE AND SUBTITLE

5. FUNDING NUMBERS

Damage Mechanisms in Bithermal and Thermomechanical Fatigue of Haynes 188

\section{AUTHOR(S)}

WU-553-13-00

Sreeramesh Kalluri and Gary R. Halford

7. PERFORMING ORGANIZATION NAME(S) AND ADDRESS(ES)

National Aeronautics and Space Administration

Lewis Research Center

Cleveland, Ohio 44135-3191

8. PERFORMING ORGANIZATION REPORT NUMBER

E-6768

9. SPONSORING/MONITORING AGENCY NAMES(S) AND ADDRESS(ES)

10. SPONSORING/MONITORING AGENCY REPORT NUMBER

National Aeronautics and Space Administration

Washington, D.C. 20546-0001

NASA TM- 105381

\section{SUPPLEMENTARY NOTES}

Prepared for the Symposium on Thermo-Mechanical Fatigue Behavior of Materials sponsored by the American Society for Testing and Materials, San Diego, California, October 16, 1991. Sreeramesh Kalluri, Sverdrup Technology, Inc., Lewis Research Center Group, 2001

Aerospace Parkway, Brook Park, Ohio 44142; Gary R. Halford, NASA Lewis Research Center. Responsible person, Sreeramesh Kalluri, (216) 433-6727.

\begin{tabular}{|l|l}
\hline 12a. DISTRIBUTION/AVAILABILITY STATEMENT & 12b. DISTRIBUTION CODE
\end{tabular}

Unclassified - Unlimited

Subject Category 39

13. ABSTRACT (Maximum 200 words)

Post failure fractographic and metallographic studies were conducted on Haynes 188 specimens fatigued under bithermal and thermomechanical loading conditions between 316 and $760{ }^{\circ} \mathrm{C}$. Bithermal fatigue specimens examined included those tested under high strain rate in-phase and out-of-phase, tensile creep in-phase, and compressive creep out-of-phase loading conditions. Specimens tested under in-phase and out-of-phase thermomechanical fatigue were also examined. The nature of failure mode (transgranular versus intergranular), the topography of the fracture surface, and the roles of oxidation and metallurgical changes were investigated for each type of bithermal and thermomechanical test.

14. SUBJECT TERMS

Damage mechanisms; Bithermal fatigue; Thermomechanical fatigue; Fractography;

Metallography; Oxidation; Cobalt-base superalloy

15. NUMBER OF PAGES

18

16. PRICE CODE

$\mathrm{A} 03$

17. SECURITY CLASSIFICATION OF REPORT

Unclassified

18. SECURITY CLASSIFICATION OF THIS PAGE

Unclassified
19. SECURITY CLASSIFICATION OF ABSTRACT Unclassified 

National Aeronautics and Space Administration

Lewis Research Center

Cleveland, Ohio 44135

Otticial Business

Penalty for Private Use $\$ 300$
FOURTH CLASS MAIL

ADDRESS CORRECTION REQUESTED
|||||

A Fees Paid National Aeronautics an Space Administration NASA 45 